\title{
Comparison of the amount of apically extruded debris produced by four retreatment techniques: an ex vivo study
}

\author{
Cristiane Ferreira Alfenas, ${ }^{1}$ Inês de Fátima de Azevedo Jacinto Inojosa, ${ }^{1}$ Júlio César de Azevedo Carvalhal, ${ }^{1}$ Mariana Teixeira Maneschy Faria, ${ }^{1}$ Fernanda \\ Freitas Lins, ${ }^{1}$ Lucio de Souza Gonçalves, ${ }^{1}$ Mônica Aparecida Schultz Neves ${ }^{1}$ \\ 'Departament of Endodontics, Faculty of Dentistry, Estácio de Sá University, Rio de Janeiro, RJ, Brazil \\ - Conflicts of interest: none declared.
}

ABstract

Objective: the aim of this study was to compare the amount of apically extruded debris during the removal of root canal filling material using nickel-titanium rotary retreatment instruments and Hedström files. Material and Methods: sixty mandibular incisors with a single canal were instrumented and obturated by cold lateral compaction. For retreatment, specimens were randomly divided into four groups $(n=15)$ : Hedström files with or without solvent; $D$-Race system and Mtwo retreatment system. Debris extruded apically during the removal of canal filling material was collected into preweighed Eppendorf tubes. The tubes were then stored in an incubator at $70^{\circ} \mathrm{C}$ for 5 days. The weight of the dry extruded debris was established by subtracting the preretreatment and postretreatment weight of the Eppendorf tubes for each group. The mean weights of extruded material were analyzed by one-way ANOVA. Results: the results showed that all retreatment techniques caused apical extrusion of debris, but no statistically significant difference was observed between groups ( $p>0.05)$. Conclusion: under the conditions of this study, all retreatment techniques caused apical debris extrusion.

Keywords: Endodontics; Retreatment; Instrumentation.

\section{Introduction}

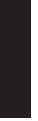
n Endodontics, some cases of treatment failure require new interventions. The main cause of endodontic failure is the persistence of bacteria in the root canal system, resulting in maintenance of periapical disease. In most of these cases, the first choice is the non-surgical retreatment, which consists of removing the root filling material followed by new instrumentation of the root canal and insertion of a new gutta-percha cone and endodontic sealer. ${ }^{1,2}$

During endodontic retreatment, some debris containing necrotic tissue, infected dentin and gutta-percha, and even bacteria, may be extruded through the apical foramen into the periradicular tissues. ${ }^{3,4}$

Many techniques with rotary nickel-titanium (NiTi) instruments ${ }^{3-6}$ and endodontic hand instruments using chemical solvents have been proposed for removing root filling materials $^{7-9}$ and, depending on the technique selected, the amount of debris may vary. This may lead to consequences ranging from slight inflammation to post-operatory flareup, as well as persistence of the periapical disease. ${ }^{10}$

Some engine-driven instruments have been manufactured exclusively for endodontic retreatment. Therefore, this ex vivo study aims to quantitatively evaluate the amount of debris apically extruded during the removal of root canal filling material, using two rotary NiTi retreatment systems or Hedström files.

\section{Material and Methods}

All specimens used in this study were provided by the Tooth Bank of Estácio de Sá University. The research protocol was approved by the ethics committee of the same institution (process number 1.451.242).
Sixty human permanent mandibular incisors were analyzed by digital radiography (Schick Tech Inc, Long Island City, NY, USA) in the buccal and proximal directions to ensure the following inclusion criteria: a single root canal, a completely formed apex, and a root canal curvature less than 5 degrees, as previously described by Schneider. ${ }^{11}$ Teeth with visible root caries, fractures or cracks, signs of internal or external resorption or calcification were excluded from the study. The soft tissue remnants were removed from the outer surface of the root using a hand scaler. Teeth were kept immersed in saline solution until the experiment was carried out.

After coronal preparation with high-speed burs, root canal patency was established with \#10, \#15, and \#20 K-files stainless steel (SS) (Dentsply Maillefer, Ballaigues, Switzerland). The specimens were sectioned with a diamond disc (Dentorium, Farmingdale, NY, USA) and the crowns were removed to standardize the root lengths to $19 \mathrm{~mm}$. The working length was established by subtracting one millimeter from the length of the file when its tip was visible at the apical foramen.

Gates-Glidden drills \#2 and \#3 (VDW, Munich, Germany) and SS K-files were used to prepare the cervical and middle thirds of the canals, according to the balancing forces technique described by Roane et al. ${ }^{12}$ The apical preparation was completed with a SS K-file \#35 to the working length, to configure the apical seat. Step back shaping was performed with \#40 through \#70 SS K-files. At each instrument change, the canals were irrigated with $2 \mathrm{~mL} 2.5 \%$ sodium hypochlorite $(\mathrm{NaOCl})$ with a syringe and a $29-\mathrm{G}$ NaviTip irrigation needle (Ultradent, South Jordan, UT, USA). Canal patency was established using a \#10 K-file through the apical fora- 
men. After concluding the preparation, the canals were irrigated with $5 \mathrm{~mL} \mathrm{17 \%}$ EDTA for 1 minute and subsequently rinsed with $10 \mathrm{~mL}$ distilled water.

\section{Root Canal Obturation}

The root canals were dried with sterile paper points and obturated using 0.02/35 master gutta-percha cone (Dentsply Ind. e Com. Ltda., Petrópolis, RJ, Brazil) and Sealer 26 (Dentsply Ind. e Com. Ltda., Petrópolis, RJ, Brazil) by the lateral compaction technique. The quality of the obturation was evaluated by mesiodistal and buccolingual radiographs. Obturation deemed as adequate was homogeneous throughout the entire root canal length, with no voids. Following that, $1 \mathrm{~mm}$ of obturating material was removed from the cervical third and the area was filled with Coltosol (Coltene, Rio de Janeiro, RJ, Brazil). The specimens were wrapped in a piece of gauze moistened with distilled water to prevent dehydration, and stored at $37^{\circ} \mathrm{C}$ for 2 weeks to allow the sealers to set. All procedures were conducted by the same operator.

\section{Collection of Debris}

A similar experimental model was used for collecting extruded debris as previously described. ${ }^{3}$ Each specimen was inserted into an unlidded Eppendorf tube, which was then attached to a glass flask through a rubber plug. A 25-gauge needle was inserted into the rubber plug to equalize the pressure inside the tube with the atmospheric pressure outside (Figure 1). Finally, the debris-collecting apparatus was covered with a rubber dam. Prior to endodontic retreatment, all specimens were weighed to $10^{-5}$ precision using an analytical microbalance (Toledo do Brasil Indústria de Balanças Ltda, São Bernardo do Campo, SP, Brazil). Three consecutive weighings were performed and the average weight was recorded.

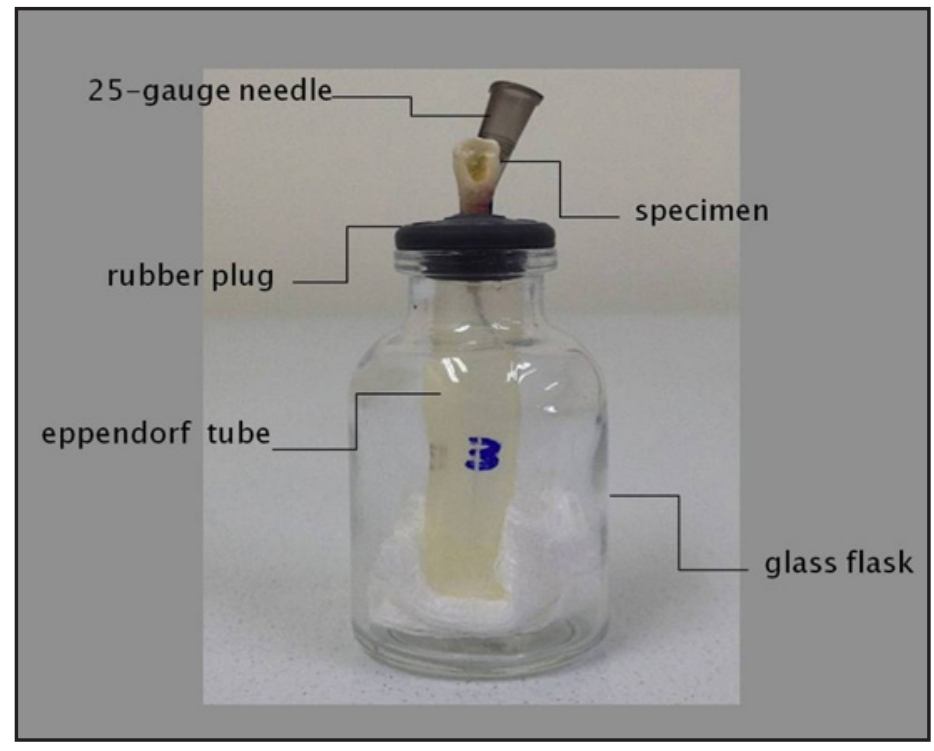

Figure 1. Experimental model system used to evaluate debris extrusion

\section{Experimental Groups}

After removal of the temporary filling material, the specimens were randomly divided into four equal groups $(\mathrm{n}=15)$ according to the retreatment procedures.

Group I - Hedström files: the root canal filling material was removed from the cervical third with \#3 and \#2 Gates-Glidden drills, and the remaining obturating material was removed up to $1 \mathrm{~mm}$ from the working length by using \#30, \#25, \#20, and \#15 Hedström files in a circumferential motion. Apical preparation was finalized by using \#40 K-file to the working length in a filing motion.

Group II - Hedström files with solvent: $0.1 \mathrm{~mL}$ of eucalyptol (Biodinâmica LTDA, Ibiporã, PR, Brazil) was placed on the entrance of the canal to dissolve the gutta-percha. The subsequent steps were the same as those performed for Group I.

Group III - D-Race system (FKG Dentaire, La Chauxde-Fonds, Switzerland): DR1 (30/.10) NiTi instrument was used in the cervical third and the initial portion of the middle third; DR2 (25/.04) NiTi instrument up to the working length, and 40/.04 BioRace (BR5) (FKG Dentaire, La Chauxde-Fonds, Switzerland) for apical preparation, according to the manufacturer's instructions.

Group IV - Mtwo R retreatment files (VDW, Munich, Germany): removal of the root canal filling material was achieved with Mtwo R2 (25/05) in the entire working length, according to the manufacturer's instructions. Apical preparation was performed with Reciproc R40 (40/.06) (VDW, Munich, Germany), also according to the manufacturer's instructions.

During instrumentation, each specimen, regardless of which group it belonged to, was irrigated with a total of 5 $\mathrm{mL}$ of distilled water with the aid of a 29-G NaviTip irrigation needle attached to a $5 \mathrm{~mL}$ syringe. In Group II, $0.1 \mathrm{~mL}$ of eucalyptol was used prior to the irrigation with distilled water.

Each sequence of instruments was used in five root canals. Each time an instrument was removed from the canal, and then it was inspected, cleaned, and discarded if any sign of plastic deformation was detected. Retreatment was considered as completed when foraminal patency was achieved, no root canal filling material was present on the instrument shaft, and root canal walls were smooth.

\section{Evaluation of Apically Extruded Debris}

A second blinded operator evaluated the amount of apically extruded debris. After retreatment, the Eppendorf tubes were removed from the glass flasks and the debris were attached to the external apical surface; the specimens were collected by washing with $1 \mathrm{~mL}$ of distilled water. The tubes were kept in an incubator at $70^{\circ} \mathrm{C}$ for 5 days to evaporate the distilled water before weighing. Specimens were weighed before and after retreatment, in triplicate. 


\section{Statistical Analysis}

All statistical tests were performed using Statistical Package for the Social Sciences (SPSS) software, version 21.0 (IBM, SP, Brazil). Normality distribution of all quantitative variables was verified using the Kolmogorov-Smirnov and Shapiro-Wilk tests and graphical analysis. The mean amounts of apically extruded debris in each of the four groups were compared by one-way analysis of variance (ANOVA). The statistical significance level of $5 \%(\mathrm{P}<0.05)$ was established for all analyses.

\section{Results}

All experimental groups showed apical extrusion of debris, with no statistically significant differences between the groups $(\mathrm{P}>0.05)$. The means and standard deviations for each group are presented in Table 1.

Table 1. Mean amounts of apically extruded debris, in grams

\begin{tabular}{l|c|c|c}
\hline Group & N & Mean(g) & Standard deviation \\
\hline Hedstrom & 15 & $0.00272^{\mathrm{a}}$ & \pm 0.00159 \\
\hline Hed+Solv & 15 & $0.00226^{\mathrm{a}}$ & \pm 0.00171 \\
\hline DRace Tet & 15 & $0.00237^{\mathrm{a}}$ & \pm 0.00109 \\
\hline Mtwo Ret & 15 & $0.00197^{\mathrm{a}}$ & \pm 0.00110 \\
\hline
\end{tabular}

Values with the same letters were not statistically different at $P=.05$.

\section{Discussion}

During endodontic retreatment, microorganisms and their products, contaminated dentin filings, chemicals, and obturating materials may be extruded through the apical foramen. This may exacerbate the inflammatory response, contributing for postoperative pain. ${ }^{10}$ Therefore, minimal apical extrusion of debris is desirable to avoid periapical tissue inflammation or even development of an infection process. $^{13}$

The protocols of this research were instituted aiming to reduce the number of variables involved in the endodontic retreatment: all specimens were permanent teeth with a single root canal and mature apex, all canals were prepared by a single operator, and the amount of irrigant used was the same for all the groups. To standardize the length of the roots in $19 \mathrm{~mm}$, the crowns of all specimens were removed.

Distilled water was chosen as the irrigant to prevent formation of sodium hypochlorite crystals, which might have remained among the debris after the solution evaporation, thus altering the results. ${ }^{14}$

The use of eucalyptol as gutta-percha solvent during endodontic retreatment is recommended by several authors; ${ }^{15-17}$ nonetheless, other studies have demonstrated that canals may be cleaned solely through the mechanical action of the instruments. ${ }^{18-20}$ Since the current literature has not reached a consensus on the need for a solvent during endodontic retreatment, its use seems to be based mostly on personal preference. ${ }^{21}$

Turker et al..$^{22}$ evaluated the amount of debris extruded during retreatment of root canals obturated by the single cone or the lateral compaction techniques, with or without the use of solvent. Their results showed that the amounts of extruded debris were similar for both techniques, and that the group in which solvent was not used had a greater amount of extruded debris.

According to some studies, NiTi rotary instruments promote less apical extrusion than Hedström files due to the crown-down approach and instrument design, both of which favor removal of debris through the root canal. ${ }^{23,24}$ According to the results from our study, all groups evaluated had apical extrusion of debris with no statistically significant difference between the groups, which agrees with other studies. ${ }^{7,8,25}$

Conversely, Çanakçi et al. ${ }^{26}$ demonstrated that Mtwo R instruments promoted greater apical extrusion of debris compared to $\mathrm{D}$-RaCe instruments. The authors attributed these results to the differences in instrument tip design: Mtwo has active tips, while D-RaCe files feature a non-cutting safety tip.

Topçuoglu et al. ${ }^{4}$ evaluated Hedström files for endodontic retreatment and observed greater apical debris extrusion. According to these authors, the greater the instrument taper, the greater the amount of debris extruded apically. To avoid this bias, in our study all root canal preparations were finalized with \#40 K-file.

According to Hülsmann \& Bluhm, ${ }^{27}$ their results showed no significant differences in the amount of apical extrusion among different techniques. These authors used semiquantitative methodology, in which scores were attributed to each technique, aiming to detect minimal differences between the techniques tested. In our study, despite the fact that a precision balance was used for all measurements, our results were similar for all techniques.

It is important to exercise caution when extrapolating these results into clinical practice. In experimental conditions, the apex is suspended inside an empty tube, while in an in vivo clinical scenario, the tooth is surrounded by periradicular tissues or granulomas, which offer some resistance to the extrusion of debris through the apex. ${ }^{27}$ Some studies $^{28,29}$ used a sponge to simulate the apical barrier; however, this material may absorb some of the irrigant and debris, altering the results of the study.

Apical extrusion of debris during endodontic retreatment occurs frequently, regardless of the technique employed. The amount of debris extruded does not appear to be correlated with a specific technique nor with the instrument selected for removal of the root canal filling material. ${ }^{8,15,21}$ 
Regarding movement, recent studies have shown that rotatory or reciprocating movement does not have significant differences in relation to extrusion of debris and root filling removal during root canal retreatment. ${ }^{30,31}$ In our research, although the smaller extrusion occurred in the retreatment group with Mtwo and Reciproc instruments, this difference was not statistically significant. This result may have been due to the association of instruments with different kinematics, where continuous rotation was used to remove the root filling material and reciprocating movement to enlarge apical third, causing less extrusion than the techniques that used a single type of movement.

\section{Conclusion}

Within the limitations of this ex vivo study, all tested techniques promoted apical extrusion of debris. There was no significant difference among the 4 retreatment techniques in the amount of debris extruded apically.

\section{References}

1. Stabholz A, Friedman S. Endodontic retreatment-case selection and technique. Part 2: Treatment planning for retreatment. J Endod. 1988;14(12):607-14. 2. Sjogren U, Hagglund B, Sundqvist G, Wing K. Factors affecting the longterm results of Endodontic treatment. J Endod. 1990;16(10):498-504.

3. Myers GL, Montgomery S. A comparison of weights of debris extruded apically by conventional filing and canal master techniques. J Endod. 1991;17(6):275-9.

4. Topçuoğlu HS, Aktı A, Tuncay Ö, Dinçer AN, Düzgün S, Topçuoğlu G. Evaluation of debris extruded apically during the removal of root canal filling material using ProTaper, D-RaCe, and R-Endo rotary nickel-titanium retreatment instruments and hand files. J Endod. 2014;40(12):2066-9.

5. Silva EJ, Sá L, Belladonna FG, Neves AA, Accorsi-Mendonça T, Vieira VT, et al. Reciprocating versus rotary systems for root filling removal: assessment of the apically extruded material. J Endod. 2014;40(12):2077-80.

6. Dincer AN, Er O, Canakci BC. Evaluation of apically extruded debris during root canal retreatment with several NiTi systems. Int Endod J. 2015;48(12):1194-8.

7. Unal GC, Kaya BU, Taç AG, Keçeki AD. A comparison of the efficacy of conventional and new retreatment instruments to remove gutta-percha in curved root canals: an ex vivo study. Int Endod J. 2009;42(4):344-50.

8. Schirrmeister JF, Wrbas KT, Schneider FH, Altenburger MJ, Hellwig E. Effectiveness of a hand file and three nickel-titanium rotary instruments for removing gutta-percha in curved root canals during retreatment. Oral Surg Oral Med Oral Pathol Oral Radiol Endod. 2006;101(4):542-7.

9. Somma F, Cammarota G, Plotino G, Grande NM, Pameijer CH. The effectiveness of manual and mechanical instrumentation for the retreatment of three different root canal filling materials. J Endod. 2008;34(4):466-9.

10. Siqueira JF Jr. Microbial causes of endodontic flare-ups. Int Endod J. 2003;36(7):453-63.

11. Schneider SW. A comparison of canal preparations in straight and curved root canals. Oral Surg Oral Med Oral Pathol. 1971;32(2):271-5.

12. Roane JB, Sabala CL, Duncanson MG Jr. The "balance force" concept for instrumentation of curved canals. J Endod. 1985;11(5):203-11.

13. Huang X, Ling J, Wei X, Gu L. Quantitative evaluation of debris extruded apically by using ProTaper Universal Tulsa Rotary System in endodontic retreatment. J Endod. 2007;33(9):1102-5.

14. Tanalp J, Gungor T. Apical extrusion of debris: a literature review of an inherent occurrence during root canal treatment. Int Endod J. 2014;47(3):211-21.

15. Betti LV, Bramante CM. Quantec SC rotary instruments versus hand files for gutta-percha removal in root canal treatment. Int Endod J. 2001;34(7):514-9.

16. Scelza MF, Coil JM, Maciel AC, Oliveira LR, Scelza P. Comparative SEM evaluation of three solvents used in endodontic retreatment: an ex vivo study. J Appl Oral Sci. 2008;16(1):24-9.
17. Ferreira JJ, Rhodes JS, Ford TR. The efficacy of gutta-percha removal using ProFiles. Int Endod J. 2001;34(4):267-74.

18. Sae-Lim V, Rajamanickam I, Lim BK, Lee HL. Effectiveness of ProFile .04 taper rotary instruments in endodontic retreatment. J Endod. 2000;26(2):100-4.

19. Gu LS, Ling JQ, Wei X, Huang XY. Efficacy of ProTaper Universal rotary retreatment system for gutta-percha removal from root canals. Int Endod J. 2008;41(4):288-95.

20. Takahashi CM, Cunha RS, de Martin AS, Fontana CE, Silveira CFM, Bueno CES. In vitro evaluation of the effectiveness of ProTaper universal rotary retreatment system for gutta-percha removal with or without a solvent. J Endod. 2009;35(11):1580-3.

21. Duncan HF, Chong BS. Removal of root filling materials. Endod topics. 2011;19(1):33-57.

22. Turker SA, Uzunoglu E, Saglam BC. Evaluation of the amount of apically extruded debris during retreatment of root canals filled by different obturation techniques. Niger J Clin Pract. 2015;18(6):802-6.

23. Zarrabi MH, Bidar M, Jafarzadeh H. An in vitro comparative study of apically extruded debris resulting from conventional and three rotary instrumentation techniques. J Oral Sci. 2006;48(2):85-8.

24. Leonardi LE, Atlas DM, Raiden G. Apical extrusion of debris by manual and mechanical instrumentation. Braz Dent J. 2007;18(1):16-9.

25. Saad AY, Al-Hadlaq SM, Al-Katheeri NH. Efficacy of two rotary NiTi instruments in the removal of gutta-percha during root canal retreatment. J Endod. 2007;33(1):38-41.

26. Çanakçi BC, Ustun Y, Er O, Genc Sen O. Evaluation of apically extruded debris from curved root canal filling removal using 5 nickel-titanium systems. J Endod. 2016;42(7):1101-4.

27. Hülsmann M, Bluhm V. Efficacy, cleaning ability and safety of different rotary NiTi instruments in root canal retreatment. Int Endod J. 2004;37(7):468-76.

28. Hachmeister DR, Schindler WG, Walker WA 3rd, Thomas DD. The sealing ability and retention characteristics of mineral trioxide aggregate in a model of apexification. J Endod. 2002;28(5):386-90.

29. Martin RL, Monticelli F, Brackett WW, Loushine RJ, Rockman RS, Ferrari $M$, et al. Sealing properties of mineral trioxide aggregate orthograde apical plugs and root fillings in an in vitro apexification model. J Endod. 2007;33(3): 272-5.

30. Silva EJ, Orlowsky NB, Herrera DR, Machado R, Krebs RL, Coutinho-Filho TS. Effectiveness of rotatory and reciprocating movements in root canal filling material removal. Braz Oral Res. 2015;29:1-6.

31. Silva EJ, Brito ME, Ferreira VD, Belladonna FG, Neves AA, Senna PM, et al. Cytotoxic effect of the debris apically extruded during three different retreatment procedures. J Oral Sci. 2016;58(2):211-7. 


\section{Mini Curriculum and Author's Contribution}

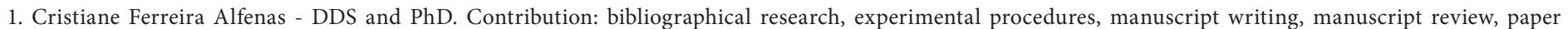
submission.

2. Inês de Fátima de Azevedo Jacinto Inojosa - DDS and PhD. Contribution: bibliographical research, experimental procedures, manuscript writing.

3. Júlio César de Azevedo Carvalhal - DDS and PhD. Contribution: bibliographical research, experimental procedures, manuscript writing.

4. Mariana Teixeira Maneschy Faria - DDS and PhD. Contribution: bibliographical research, experimental procedures, manuscript writing.

5. Fernanda Freitas Lins - DDS and PhD. Contribution: bibliographical research, manuscript writing.

6. Lucio de Souza Gonçalves - DDS and PhD. Contribution: bibliographical research, statistical analysis, manuscript writing, manuscript review.

7. Mônica Aparecida Schultz Neves - DDS and PhD. Contribution: bibliographical research, manuscript writing, manuscript review, work supervisor.

Submitted: 10/25/2017 / Accepted for publication: 12/05/2017

Corresponding Author

Cristiane Ferreira Alfenas

E-mail: calfenas@hotmail.com 